\title{
Influence of Tinnitus on Auditory Spectral and Temporal Resolution and Speech Perception in Tinnitus Patients
}

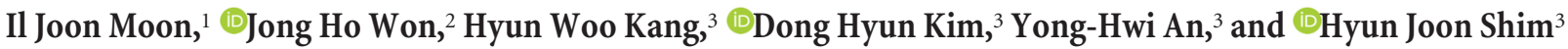 \\ ${ }^{1}$ Department of Otorhinolaryngology and Head and Neck Surgery, Samsung Medical Center, Sungkyunkwan University, School of Medicine, Seoul 135-710, \\ Korea, ${ }^{2}$ Department of Audiology and Speech Pathology, University of Tennessee Health Science Center, Knoxville, Tennessee 37996, and ${ }^{3}$ Department of \\ Otorhinolaryngology and Head and Neck Surgery, Eulji University School of Medicine, Eulji Medical Center, Seoul 139-711, Korea
}

Although cochlear damage is believed to trigger the perception of tinnitus in the central auditory system, its pathophysiological mechanism is still unclear. We aimed to investigate the pathophysiology of tinnitus using psychoacoustic assessments of auditory spectral and temporal resolution and speech perception in noise. Human subjects with tinnitus and symmetric hearing thresholds were divided into three groups: nine unilateral tinnitus subjects with normal hearing thresholds (Group 1), 12 unilateral tinnitus subjects with hearing loss (HL; Group 2), and nine bilateral tinnitus subjects with HL. Fifteen normal-hearing subjects without tinnitus were also tested as a control group. Four different tests were administered: (1) the spectral-ripple discrimination (SRD) test, (2) the temporal modulation detection (TMD) test, (3) the Schroeder-phase discrimination (SPD) test, and (4) the speech recognition threshold (SRT) in noise test. There were no significant differences in SRD, TMD, and SPD between the tinnitus-affected ears (TEs) and non-tinnitus ears (NTEs) in Groups 1 and $2(p>0.05)$. In contrast, the TEs showed poorer SRTs than the NTEs in these two subject groups $(p=0.022$ and 0.049$)$. No inferiority of spectral/temporal resolution in TEs compared with NTEs suggests that there may be no more outer hair cell (OHC) damage on the tinnitus side given that damaged OHCs are associated with broadening the auditory filters. The decoupling of the SRT results from the spectral/ temporal resolution data could imply that the occurrence of tinnitus does not depend upon the degree of damage to the OHCs, but rather upon different plastic changes in the central auditory system after cochlear damage.

Key words: psychoacoustics; spectral resolution; speech perception; temporal resolution; tinnitus

\section{Significance Statement}

We can easily find unilateral tinnitus patients who have symmetric hearing thresholds. Our research question was what kind of difference would be responsible for the tinnitus in the tinnitus-affected ears but not in the non-tinnitus ears of subjects with symmetric hearing thresholds. The answer to this fundamental question could help us to understand the pathophysiology of tinnitus. We evaluated the potential influence of tinnitus upon the subjects' auditory spectral and temporal resolution and speech perception in noise by comparing these psychoacoustic performances between tinnitus-affected ears and non-tinnitus ears in the same subjects.

\section{Introduction}

Tinnitus subjects with normal audiograms have long been used to investigate the pathophysiology of tinnitus. However, normal hearing thresholds do not necessarily indicate the absence of co-

Received Dec. 12, 2014; revised Aug. 25, 2015; accepted Sept. 11, 2015.

Author contributions: J.H.W., Y.-H.A., and H.J.S. designed research; D.H.K. performed research; H.W.K., D.H.K., and H.J.S. analyzed data; I.J.M., J.H.W., and H.J.S. wrote the paper.

This research was supported by EMBRI Grant 2012 EMBRISN0005 from Eulji University. The SPD test program was provided by the Rubinstein Laboratory at the University of Washington.

The authors declare no competing financial interests.

Correspondence should be addressed to Hyun Joon Shim, Department of Otolaryngology, Eulji University School of Medicine, Eulji Medical Center, 68 Hangeulbiseok-Ro, Nowongu, Seoul 139-711, Korea. E-mail: eardoc11@naver.com.

DOI:10.1523/JNEUROSCI.5091-14.2015

Copyright $\odot 2015$ the authors $\quad 0270-6474 / 15 / 3514260-10 \$ 15.00 / 0$ chlear damage or complete innervation of central auditory system (Leger et al., 2012, 2014). In fact, the cochlea, which can hear the sound at $0 \mathrm{~dB}$, might have better hair cell status than the cochlea, which is able to hear the sound at $20 \mathrm{~dB}$ (Tyler et al., 2014). Several studies have demonstrated that tinnitus subjects with normal audiograms show increased hearing thresholds at extended high frequencies $>8 \mathrm{kHz}$ compared with normalhearing subjects without tinnitus (Shim et al., 2009; Fabijanska et al., 2012). Some investigators doubt that subtle damage to the outer hair cells (OHCs) that alters otoacoustic emissions can cause tinnitus (Shiomi et al., 1997; Onishi et al., 2004; Gouveris et al., 2005; Job et al., 2007; Ami et al., 2008). Other investigators have suggested that there could be central deafferentation despite normal audiogram and a marked reduction in the amplitude of 
the wave I potential originating from the auditory nerve (Schaette and McAlpine, 2011) or increased tone-detection thresholds in threshold-equalizing noise at high sound intensity in subjects with normal audiograms (Weisz et al., 2006). Studies of tinnitus subjects with normal audiograms typically suggest that tinnitus may even be triggered by very subtle damage to the cochlea, but some cases do not induce tinnitus despite the presence of cochlear damage. Maladaptive neuronal plasticity of the central auditory system triggered by preceding cochlear damage is believed to be one of the general neurophysiologic models that can explain the selective occurrence of tinnitus after cochlear damage. Reduced signal transduction from damaged hair cells may cause a reduction in the lateral inhibition of central auditory system, followed by increased synchronous firing or spontaneous activity in the auditory neurons at the edge of the characteristic frequency (Preece et al., 2003; Bartels et al., 2007; Noreña and Farley, 2013). However, some patients show tinnitus pitch that does not correspond to their maximum hearing loss (HL) (Pan et al., 2009), so the connection between the peripheral damage and subsequent adaptation of the central auditory system is still unclear.

In this study, we did not target tinnitus subjects with normal audiograms because the normal hearing range $(0-20 \mathrm{~dB} \mathrm{HL})$ is too wide and, at the frequencies $>8 \mathrm{kHz}$, it is very difficult to determine the normal threshold. Instead, tinnitus patients who have symmetric hearing thresholds were considered as test subjects regardless of their hearing thresholds. We investigated the pathophysiology of tinnitus using psychoacoustic assessments to examine the potential influence of tinnitus upon the subjects' auditory spectral and temporal resolution and speech perception in noise. To exclude individual variations, the psychoacoustic performance between tinnitus-affected ears (TEs) and nontinnitus ears (NTEs) within the same subjects were compared. We aimed to understand potential differences that may be responsible for tinnitus in the TEs but not in the NTEs of subjects with symmetric hearing thresholds

In the current study, we hypothesized that tinnitus could develop in the TEs with a minimal peripheral damage that may not even give rise to any threshold difference compared with the NTEs within the same subjects. Alternatively, it is possible that, despite the same degree of cochlear (i.e., peripheral) damage, adaptive processes of central auditory system could exclusively affect ears on one side (i.e., TEs), creating TEs and NTEs in the same subjects. To test this hypothesis, the auditory spectral and temporal resolution and speech perception in noise of TEs and NTEs were compared. If there is any difference in spectral resolution and/or temporal resolution of hearing between the TEs and NTEs of unilateral tinnitus subjects with symmetric hearing thresholds, it may be attributed to "a little more peripheral damage" primarily to the cochlea.

\section{Materials and Methods}

\section{Subjects}

We enrolled a total of 30 tinnitus subjects and 15 normal subjects who were native speakers of Korean. The tinnitus subjects were divided into three different groups as follows.

Group 1. Nine unilateral tinnitus subjects (six males and three females, mean age $=28.22 \pm 9.22$ years) with normal and symmetric hearing thresholds defined as $(1) \leq 20 \mathrm{~dB}$ hearing level at $0.25,0.5,1,2,3,4$, and $8 \mathrm{kHz}$; (2) a binaural difference of $\leq 10 \mathrm{~dB}$ at all measured frequencies up to $8 \mathrm{kHz}$ (subjects who showed a $10 \mathrm{~dB}$ difference between two ears for $>2$ frequencies up to $8 \mathrm{kHz}$ were excluded); and (3) binaural difference of $\leq 15 \mathrm{~dB}$ at $9,11.2,12.5,14,16,18$, and $20 \mathrm{kHz}$.

Group 2. Twelve unilateral tinnitus subjects (eight males and four females, mean age $=56.08 \pm 12.92$ years) with HL and symmetric hearing thresholds defined as (1) $>20 \mathrm{~dB}$ hearing level at one or more frequencies of $0.25,0.5,1$, $2,3,4$, and $8 \mathrm{kHz}$ and (2) a binaural difference of $\leq 10 \mathrm{~dB}$ at all measured frequencies (subjects who showed a $10 \mathrm{~dB}$ difference between two ears for $>2$ frequencies up to $8 \mathrm{kHz}$ were excluded).

Group 3. Nine bilateral tinnitus subjects (four males, five females, mean age $=60.67 \pm 10.98$ years) with HL and symmetric hearing thresholds defined as the same criteria used for Group 2.

Group 4 (control). Fifteen normal subjects (six males and nine females, mean age $=44.93 \pm 9.00$ years) with normal and symmetric hearing thresholds (1) $\leq 20 \mathrm{~dB}$ hearing level at $0.25,0.5,1,2,3,4$, and $8 \mathrm{kHz},(2)$ a binaural difference of $\leq 10 \mathrm{~dB}$ at all measured frequencies up to $8 \mathrm{kHz}$ (subjects who showed a $10 \mathrm{~dB}$ difference between two ears for $>2$ frequencies up to $8 \mathrm{kHz}$ were excluded).

Figure 1 and Table 1 show the pure-tone averages (PTAs) and mean hearing thresholds at various frequencies for each subject group. The mean duration of tinnitus in Groups 1, 2, and 3 was 10.22 \pm 9.46, $60.67 \pm 75.51$, and $51.25 \pm 32.32$ months, respectively. Tinnitus characteristics are listed in Table 2.

All subjects underwent audiological tests, including pure-tone audiometry, tinnitus pitch and loudness matching, impedance audiometry, and the auditory brainstem response. With careful physical examinations of the head and neck regions, we excluded subjects suspected of having objective tinnitus or somatic tinnitus. Subjects with chronic otitis media, retrocochlear lesions, endolymphatic hydrops, or congenital ear malformation were also excluded. We also excluded subjects with tinnitus accompanied by dizziness, history of ototoxic drug use, or HL with a conductive or surgically correctible component. This study was approved by the Institutional Review Board of the Eulji Medical Center, South Korea.

\section{Procedure}

Spectral-ripple discrimination (SRD) and temporal modulation detection (TMD) were measured to evaluate spectral and temporal envelope sensitivity. Schroeder-phase discrimination (SPD) was used to measure the sensitivity to both spectral and temporal modulations (Dooling et al., 2002; Drennan et al., 2008; Lauer et al., 2009). In addition, speech recognition threshold (SRT) in background noise was measured.

All testing sessions were conducted in a sound-attenuating booth. Stimuli were presented using custom MATLAB programs with a sampling frequency of $44,100 \mathrm{~Hz}$. The stimuli were routed through an audiometer (Orbiter 922; GN Otometrics) and presented monaurally to the test ear via an inserted earphone (ER-3A; Etymotic). Four different listening tests were administered to each individual subject. The left and right ears of all subjects were tested separately. The order of the four tests was randomized within and across subjects.

\section{SRD test}

The SRD test was administered using a previously established technique (Won et al., 2007). Three rippled noise tokens with a $30 \mathrm{~dB}$ peak-to-trough ratio, two with standard ripple phase and one with inverted ripple phase, were created using 2555 tones. The spectral modulation starting phase of the full-wave-rectified sinusoidal spectral envelope was set to zero radians for standard ripple stimuli. The spectral modulation starting phase of inverted spectral-ripple stimuli were set to $\pi / 2$ radians. A bandwidth of the rippled spectrum was $100-5000 \mathrm{~Hz}$. The duration of the stimuli was $500 \mathrm{~ms}$. The order of presentation of the three tokens was randomized and the subject's task was to select the "oddball" stimulus. For normal-hearing subjects with PTA $\leq 20 \mathrm{~dB}$ hearing level, the stimuli were presented at $65 \mathrm{dBA}$. For hearing-impaired subjects with PTA $>20 \mathrm{~dB}$ hearing level, most comfortable level (MCL) for each subject was first measured using rippled noise. During testing, ripple stimuli were presented at the measured MCL for each hearing-impaired subject.

To measure SRD thresholds, a three-interval, three-alternative forced choice (3-AFC) paradigm with an adaptive two-up and one-down procedure was used. Ripple density was varied between 0.125 and 11.314 ripples per octave in equal ratio steps of 1.414 in an adaptive manner with 13 reversals that converge to the $70.7 \%$ correct point (Levitt, 1971). A level attenuation of $1-8 \mathrm{~dB}$ (in $1 \mathrm{~dB}$ increments) was randomly selected for each interval in the three-interval task. The SRD threshold for each adaptive run was calculated as the mean of the last eight reversals. The SRD threshold for each subject was the mean of three adaptive runs. 

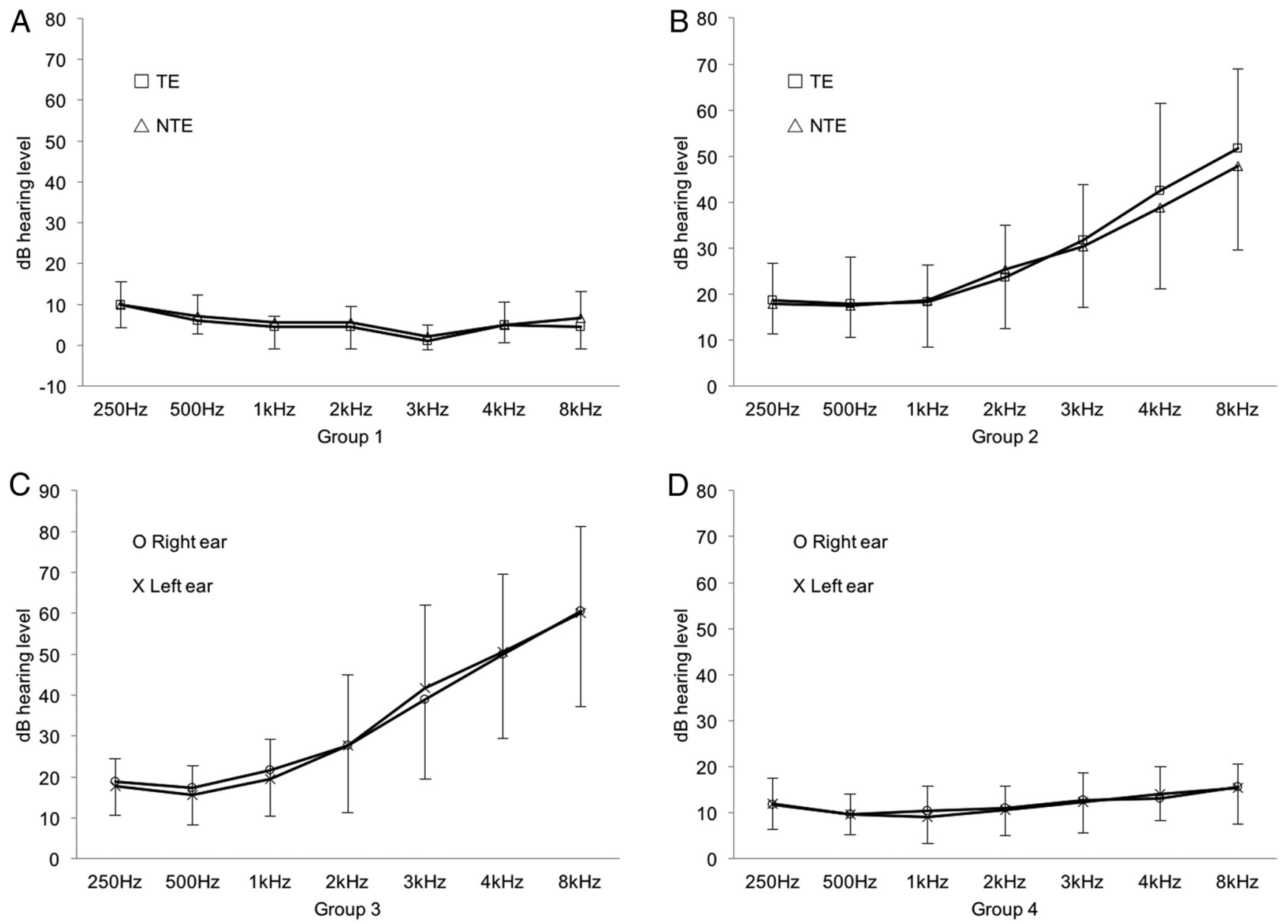

Figure 1. Mean pure-tone thresholds of measured frequencies in in each group. Group 1 included nine unilateral tinnitus subjects with normal and symmetric hearing thresholds $(A) ; G$ Group 2,12 unilateral tinnitus subjects with HL and symmetric hearing thresholds (B); Group 3, Nine bilateral tinnitus subjects with HL and symmetric hearing thresholds and 19 normal subjects (C); and Group 4 (control), 15 normal subjects with normal and symmetric hearing thresholds (D).

Table 1. Age, sex, and PTA of the subjects for the four different groups

\begin{tabular}{|c|c|c|c|c|c|c|c|c|}
\hline \multirow{5}{*}{$\begin{array}{l}\text { Sex } \\
\text { Age (years) } \\
\text { PTA (dB hearing level) }\end{array}$} & \multicolumn{2}{|l|}{ Group $1(n=9)$} & \multicolumn{2}{|l|}{ Group $2(n=12)$} & \multicolumn{2}{|l|}{ Group $3(n=9)$} & \multicolumn{2}{|c|}{ Group 4 (control, $n=15$ ) } \\
\hline & M: 6 & $\mathrm{~F}: 3$ & M: 8 & $\mathrm{~F}: 4$ & M: 4 & $\mathrm{~F}: 5$ & M: 6 & $\mathrm{~F}: 9$ \\
\hline & $28.22 \pm 9.22$ & & $56.08 \pm 12.92$ & & $60.67 \pm 10.98$ & & $44.93 \pm 9.00$ & \\
\hline & TE & NTE & TE & NTE & Right & Left & Right & Left \\
\hline & $4.03 \pm 2.71$ & $5.14 \pm 1.92$ & $22.92 \pm 9.24$ & $23.02 \pm 9.08$ & $26.39 \pm 11.58$ & $26.11 \pm 11.31$ & $10.92 \pm 4.19$ & $10.42 \pm 4.95$ \\
\hline
\end{tabular}

\section{Table 2. Characteristics of tinnitus in three different tinnitus groups}

\begin{tabular}{|c|c|c|c|c|c|}
\hline Pitch (kHz) & Duration (month) & THI score & VAS of the loudness & $\operatorname{TAS}(\%)^{a}$ & BDI \\
\hline \multicolumn{6}{|l|}{ Group 1: unilateral tinnitus subjects with normal and symmetric hearing thresholds } \\
\hline $4.00 \pm 2.45$ & $10.22 \pm 9.46$ & $49.00 \pm 28.63$ & $4.33 \pm 2.06$ & $75.66 \pm 27.89$ & $11.78 \pm 7.69$ \\
\hline \multicolumn{6}{|l|}{ Group 2: unilateral tinnitus subjects with HL and symmetric hearing thresholds } \\
\hline $5.27 \pm 2.72$ & $60.67 \pm 75.51$ & $47.00 \pm 32.79$ & $6.08 \pm 2.57$ & $91.82 \pm 13.28$ & $12.42 \pm 10.16$ \\
\hline \multicolumn{6}{|l|}{ Group 3: bilateral tinnitus subjects with HL and symmetric hearing thresholds } \\
\hline $6.38 \pm 2.62$ & $51.25 \pm 32.32$ & $50.25 \pm 38.43$ & $6.75 \pm 3.11$ & $65.00 \pm 33.38$ & $13.88 \pm 12.23$ \\
\hline
\end{tabular}

THI, Tinnitus Handicap Inventory; VAS, visual analogue scale; BDI, Beck depression inventory.

${ }^{a}$ Tinnitus awareness score (TAS) is defined as the percentage of the time the patient is aware of tinnitus for a day.

TMD test

The TMD test was performed using the method previously described by Won et al. (2011). For the modulated stimuli, sinusoidal amplitude modulation was applied to the wideband noise carrier. Two modulation frequencies were tested, 10 and $100 \mathrm{~Hz}$. The stimulus duration for both modulated and unmodulated signals were $1 \mathrm{~s}$. Modulated and unmodu- lated signals were gated on and off with $10 \mathrm{~ms}$ linear ramps and were concatenated with no gap between the two signals. The TMD threshold was measured using a 2-interval, 2-AFC paradigm. One of the intervals consisted of modulated noise and the other interval consisted of steady noise. Subjects were asked to identify the interval that contained the modulated noise. A two-down, one-up adaptive procedure was used to 
measure TMD threshold, starting with a modulation depth of $100 \%$ and decreasing in steps of $4 \mathrm{~dB}$ from the first to the fourth reversal and $2 \mathrm{~dB}$ for the next 10 reversals. For each testing run, the final 10 reversals were averaged to obtain TMD thresholds. TMD thresholds in $\mathrm{dB}$ relative to $100 \%$ modulation (i.e., $\left.20 \log _{10}\left(m_{\mathrm{i}}\right)\right)$ were obtained, where $m_{\mathrm{i}}$ indicates the modulation index. The threshold for each subject was calculated as the mean of three testing runs.

As with the SPD test, stimuli were presented at $65 \mathrm{dBA}$ for normalhearing subjects with PTA $\leq 20 \mathrm{~dB}$ hearing level. For hearingimpaired listeners with PTA $>20 \mathrm{~dB}$ hearing level, their MCLs were first measured using an unmodulated wideband noise and then stimuli were presented at the measured MCL for each subject during actual testing.

\section{SPD test}

The SPD test was implemented using the same method as that previously described by Drennan et al. (2008). Positive and negative Schroederphase stimulus pairs were created for two different fundamental frequencies $\left(F_{0}\right)$ of 100,150 , and $200 \mathrm{~Hz}$. The $F_{0}$ of Schroeder-phase harmonic complex determined a rate of frequency sweep over time. For each $F_{0}$, equal-amplitude harmonics from the $F_{0}$ up to $5 \mathrm{kHz}$ were summed. Phase values for each harmonic were determined by the following equation:

$$
\theta_{n}= \pm \pi n(n+1) / N
$$

where $\theta_{n}$ is the phase of the $n$th harmonic, $n$ is the $n$th harmonic, and $N$ is the total number of harmonics in the complex. The positive or negative sign was used for the positive or negative Schroeder-phase stimuli, respectively. A 4-interval, 2-AFC procedure was used. One stimulus (i.e., positive Schroeder-phase, test stimulus) occurred in either the second or third interval and was different from three others (i.e., negative Schroeder-phase, reference stimulus). The subject's task was to discriminate the test stimulus from the reference stimuli. To determine a total percentage correct for each $F_{0}$, the method of constant stimuli was used. In a single test run, each $F_{0}$ was presented 24 times in random order and a total percentage correct for each $F_{0}$ was calculated as the percentage of stimuli correctly identified. For each $F_{0}$, the SPD score for each subject was the mean of three testing runs.

As with the other two psychoacoustic tests, stimuli were presented at $65 \mathrm{dBA}$ for normal-hearing subjects with PTA $\leq 20 \mathrm{~dB}$ hearing level. For hearing-impaired listeners with a PTA $>20 \mathrm{~dB}$ hearing level, MCL was first measured using Schroeder-phase stimuli and then stimuli were presented at the measured MCLs for each individual hearing-impaired subject during actual testing.

\section{SRT test}

To measure SRTs in background noise, equally difficult open-set spondee words spoken by a male speaker were presented in the presence of speech-shaped, steady noise. The steady noise maskers were spectrally shaped to have the same long-term power spectrum as the spondee words. In all trials, maskers were gated on and off with $50 \mathrm{~ms}$ linear ramps $500 \mathrm{~ms}$ before and $50 \mathrm{~ms}$ after the target spondee word. The mixture of the target spondee and masker stimuli was then presented monaurally to the test ear. SRTs corresponding to the $50 \%$ intelligibility level were measured using a one-up, one-down adaptive procedure. For each testing run, subjects identified the spondee words in the presence of steadystate noise. Each test run started with a signal-to-noise ratio (SNR) of 6 $\mathrm{dB}$, for which subjects were easily able to identify the spondee word correctly. If subjects correctly repeated the spondee word, the SNR for the next spondee was decreased; otherwise, the SNR for the next spondee was increased. The level of the target spondee words was always fixed, but the level of background noise was varied in an adaptive manner. For normal-hearing subjects, the level of the target words was $65 \mathrm{dBA}$, but for hearing-impaired subjects, target spondee words were presented at their MCLs. An initial step size of $4 \mathrm{~dB}$ was used for the first two reversals in the adaptive track, after which the step size was fixed at $2 \mathrm{~dB}$ for the next six reversals. The SRT for a given run was based on the average of the SNRs corresponding to each of the last six reversals in the adaptive track. No target spondee word was repeated to any subject. Three adaptive runs were completed. The final SRT for each subject was the mean of three adaptive runs.

Analysis

For the control subjects, one side (either left or right) was chosen randomly and designated as the control ears for each normal-hearing subject. The four different test results for the TEs and NTEs of Groups 1 and 2 were compared using a paired $t$ test. The right and left TEs of Group 3 (bilateral tinnitus subjects) were also compared using a paired $t$ test. The statistical comparisons among TEs, NTEs, and control ears were performed using multiple independent $t$ tests or Mann-Whitney tests with Bonferroni's correction $(\alpha=0.05 / 3=0.017)$. The comparisons among TEs of Group 1, Group 2, and both TEs of Group 3 were done using multiple independent $t$ tests or the Mann-Whitney tests with Bonferroni's correction $(\alpha=0.05 / 6=0.008)$. Multiple linear regression analyses of SRD, TMD threshold, SPD score, and SRT on the TEs of unilateral tinnitus subjects were performed with various factors. Correlations between SRT in noise and each of the SRD thresholds and TMD thresholds were analyzed using a Pearson's correlation analysis.

\section{Results}

Tinnitus effects in Group 1: unilateral tinnitus subjects with normal and symmetric hearing thresholds

The within-subject comparison between TEs and NTEs in Group 1 revealed that there were no significant differences in SRD thresholds, TMD thresholds for $100 \mathrm{~Hz}$, and SPD scores (100, 150 , and $200 \mathrm{~Hz}$ ) between the TEs and NTEs (paired $t$ test, $p>$ 0.05 ; for $p$ values, see Fig. 2). In contrast, the TEs showed higher SRTs (i.e., poorer performance) in noise than the NTEs of unilateral tinnitus subjects (paired $t$ test, $p=0.022$; Fig. 2). TMD thresholds for $10 \mathrm{~Hz}$ showed lower TMD thresholds (better TMD performance) in the TEs than NTEs (paired $t$ test, $p=0.028$; Fig. 2 ). The multiple comparisons among the TEs, NTEs, and control ears of Group 4 with the Bonferroni correction showed that the TEs showed poorer speech perception in noise but better TMD performance $(100 \mathrm{~Hz})$ compared with the control ears of the normal subjects (independent $t$ test, $p=0.003$ and 0.005 , respectively; Table 3 ). In any other comparisons, there were no significant differences (independent $t$ test or Mann-Whitney test with the Bonferroni correction, $p>0.017 ; \alpha=0.05 / 3)$.

\section{Tinnitus effects in Group 2: unilateral tinnitus subjects with HL and symmetric hearing thresholds}

The within-subject comparison between the TEs and NTEs showed that there were no significant differences in SRD thresholds, TMD thresholds (for both 10 and $100 \mathrm{~Hz}$ ), and SPD scores $(100,150$, and $200 \mathrm{~Hz}$ ) between the TEs and NTEs (paired $t$ test $p>0.05$; for detailed $p$ values, see Fig. 3 ). In contrast, the TEs showed higher SRTs (i.e., poorer speech perception) in noise than the NTEs of the unilateral tinnitus subjects (paired $t$ test, $p=$ 0.049; Fig. 3). The multiple comparisons among the TEs, NTEs, and control ears of Group 4 with the Bonferroni correction demonstrated that higher SRTs (poorer speech perception) in noise were shown for the TEs than for the control ears (independent $t$ test, $p=0.001$; Table 4 ). In any other comparisons, there were no significant differences (independent $t$ test or Mann-Whitney test with Bonferroni's correction, $p>0.017 ; \alpha=0.05 / 3$ ).

\section{Tinnitus effects in Group 3: bilateral tinnitus subjects with HL and symmetric hearing thresholds}

The within-subject comparison between the right and left TEs showed that there was no difference in SRTs in noise (paired $t$ test, $p=0.937$; Fig. 4 ). There were no significant differences in SRD thresholds, TMD thresholds (10 and $100 \mathrm{~Hz}$ ), or SPD scores $(100$ and $200 \mathrm{~Hz}$ ) between the right and left TEs of the bilateral 

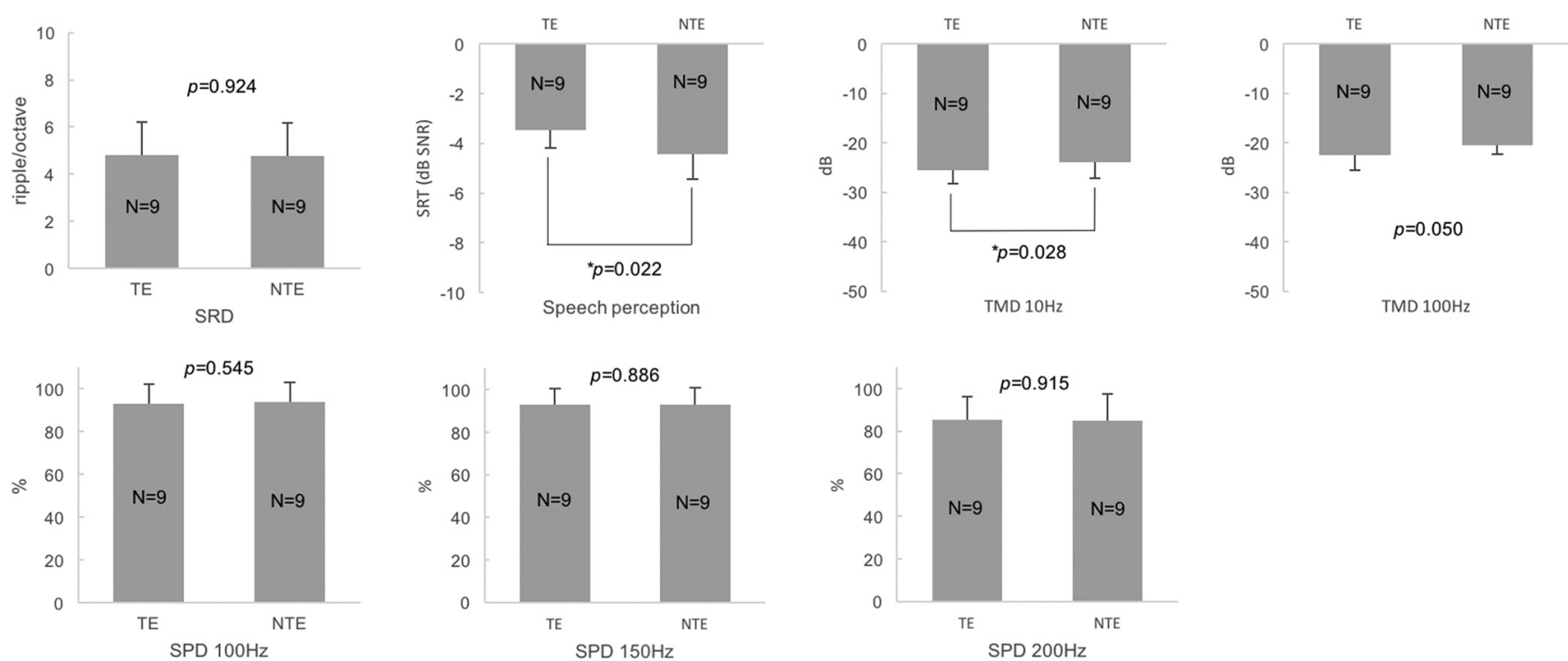

Figure 2. Comparisons of four different psychoacoustic test results between the TEs and NTEs of unilateral tinnitus subjects with normal and symmetric hearing thresholds. There were no significant differences in SRD thresholds, TMD thresholds for $100 \mathrm{~Hz}$, or SPD scores, but the TEs showed higher SRTs in noise (poorer speech perception) and showed lower TMD thresholds for $10 \mathrm{~Hz}$ (better TMD performance) than the NTEs.

Table 3. Multiple comparisons among TEs and NTEs for Group 1 and control ears for Group 4 with Bonferroni's correction $\left({ }^{*} p<0.017\right)$

\begin{tabular}{|c|c|c|c|c|c|c|c|c|c|}
\hline & $\operatorname{TEs}(n=9)$ & NTEs $(n=9)$ & & TEs $(n=9)$ & Control $(n=15)$ & & NTEs $(n=9)$ & Control $(n=15)$ & \\
\hline & Mean (SD) & Mean (SD) & $p$ value & Mean (SD) & Mean (SD) & $p$ value & Mean (SD) & Mean (SD) & $p$ value \\
\hline SRD & $4.82(1.37)$ & $4.76(1.42)$ & 0.924 & $4.82(1.37)$ & $3.23(1.85)$ & 0.037 & $4.76(1.42)$ & $3.23(1.85)$ & 0.044 \\
\hline TMD $100 \mathrm{~Hz}$ & $-22.57(2.96)$ & $-20.59(1.66)$ & 0.050 & $-22.57(2.96)$ & $-16.47(6.38)$ & $0.005^{*}$ & $-20.59(1.66)$ & $-16.47(6.38)$ & 0.030 \\
\hline SPD $100 \mathrm{~Hz}$ & $93.06(9.08)$ & 93.89 (9.28) & 0.545 & $93.06(9.08)$ & 91.35 (9.82) & 0.592 & 93.89 (9.28) & 91.35 (9.82) & 0.592 \\
\hline SPD $150 \mathrm{~Hz}$ & $92.78(7.75)$ & $93.06(7.88)$ & 0.886 & 92.78 (7.75) & 85.58 (12.84) & 0.182 & $93.06(7.88)$ & 85.58 (12.84) & 0.182 \\
\hline
\end{tabular}

*Multiple independent $t$ test or Mann-Whitney test with the Bonferroni correction, $\alpha=0.05 / 3=0.017$.
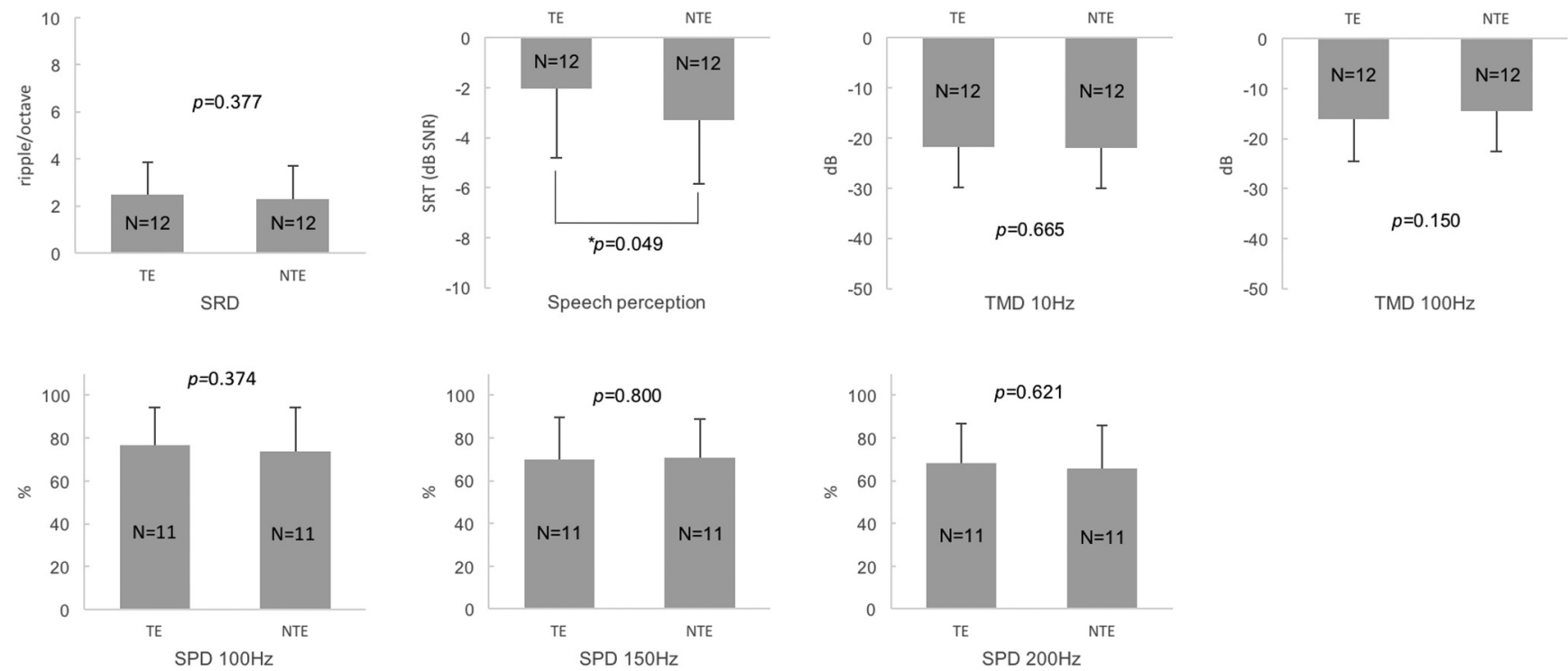

Figure 3. Comparisons of four different psychoacoustic test results between the TEs and NTEs of unilateral tinnitus subjects with HL and symmetric hearing thresholds. There were no significant differences in the SRD thresholds, TMD thresholds, or SPD scores, but the TEs showed higher SRTs in noise (poorer speech perception) than the NTES.

tinnitus subjects (paired $t$ test, $p>0.05$; Fig. 4). Only the SPD scores for $150 \mathrm{~Hz}$ showed a significant difference between the right and left TEs (paired $t$ test, $p=0.026$; Fig. 4). The multiple comparisons among the right TEs, left TEs, and the control ears of Group 4 with the Bonferroni correction, higher SRTs (poorer speech perception) in noise, and lower SPD scores for $200 \mathrm{~Hz}$ were shown for the right TEs than the control ears (independent $t$ test, $p=0.000$ and 0.004 , respectively; Table 5). Higher SRT in 
Table 4. Multiple comparisons among TEs and NTEs for Group 2 and control ears for Group 4 with Bonferroni's correction (* $p<0.017$ )

\begin{tabular}{|c|c|c|c|c|c|c|c|c|c|}
\hline & $\operatorname{TEs}(n=12)$ & NTEs $(n=12)$ & & $\operatorname{TEs}(n=12)$ & Control $(n=15)$ & \multirow[b]{2}{*}{$p$ value } & \multirow{2}{*}{$\begin{array}{l}\text { NTEs }(n=9) \\
\text { Mean }(S D)\end{array}$} & \multirow{2}{*}{$\frac{\text { Control }(n=15)}{\text { Mean }(S D)}$} & \multirow[b]{2}{*}{$p$ value } \\
\hline & Mean (SD) & Mean (SD) & $p$ value & Mean (SD) & Mean (SD) & & & & \\
\hline SRD & $2.49(1.94)$ & 2.29 (1.44) & 0.377 & $2.49(1.94)$ & $3.23(1.85)$ & 0.324 & $2.29(1.44)$ & $3.23(1.85)$ & 0.164 \\
\hline SRT & $-2.03(2.79)$ & $-3.30(2.56)$ & 0.049 & $-2.03(2.79)$ & $-5.16(1.68)$ & $0.001^{*}$ & $-3.30(2.56)$ & $-5.16(1.68)$ & 0.032 \\
\hline TMD $10 \mathrm{~Hz}$ & $-21.76(8.06)$ & $-22.03(7.96)$ & 0.665 & $-21.76(8.06)$ & $-23.60(2.26)$ & 0.077 & $-22.03(7.96)$ & $-23.60(2.26)$ & 0.557 \\
\hline TMD $100 \mathrm{~Hz}$ & $-16.05(8.45)$ & $-14.55(7.96)$ & 0.150 & $-16.05(8.45)$ & $-16.47(6.38)$ & 0.883 & $-14.55(7.96)$ & $-16.47(6.38)$ & 0.492 \\
\hline SPD $100 \mathrm{~Hz}$ & 76.82 (17.47) & $73.86(20.35)$ & 0.374 & $76.82(17.47)$ & $91.35(9.82)$ & 0.586 & $73.86(20.35)$ & $91.35(9.82)$ & 0.382 \\
\hline SPD $150 \mathrm{~Hz}$ & 70.00 (19.62) & $70.92(18.07)$ & 0.800 & 70.00 (19.62) & 85.58 (12.84) & 0.029 & $70.92(18.07)$ & $85.58(12.84)$ & 0.030 \\
\hline SPD $200 \mathrm{~Hz}$ & 68.18 (18.51) & $65.91(20.01)$ & 0.621 & 68.18 (18.51) & 77.50 (11.41) & 0.145 & $65.91(20.01)$ & 77.50 (11.41) & 0.089 \\
\hline
\end{tabular}

*Multiple independent $t$ test or Mann-Whitney test with the Bonferroni correction, $\alpha=0.05 / 3=0.017$.
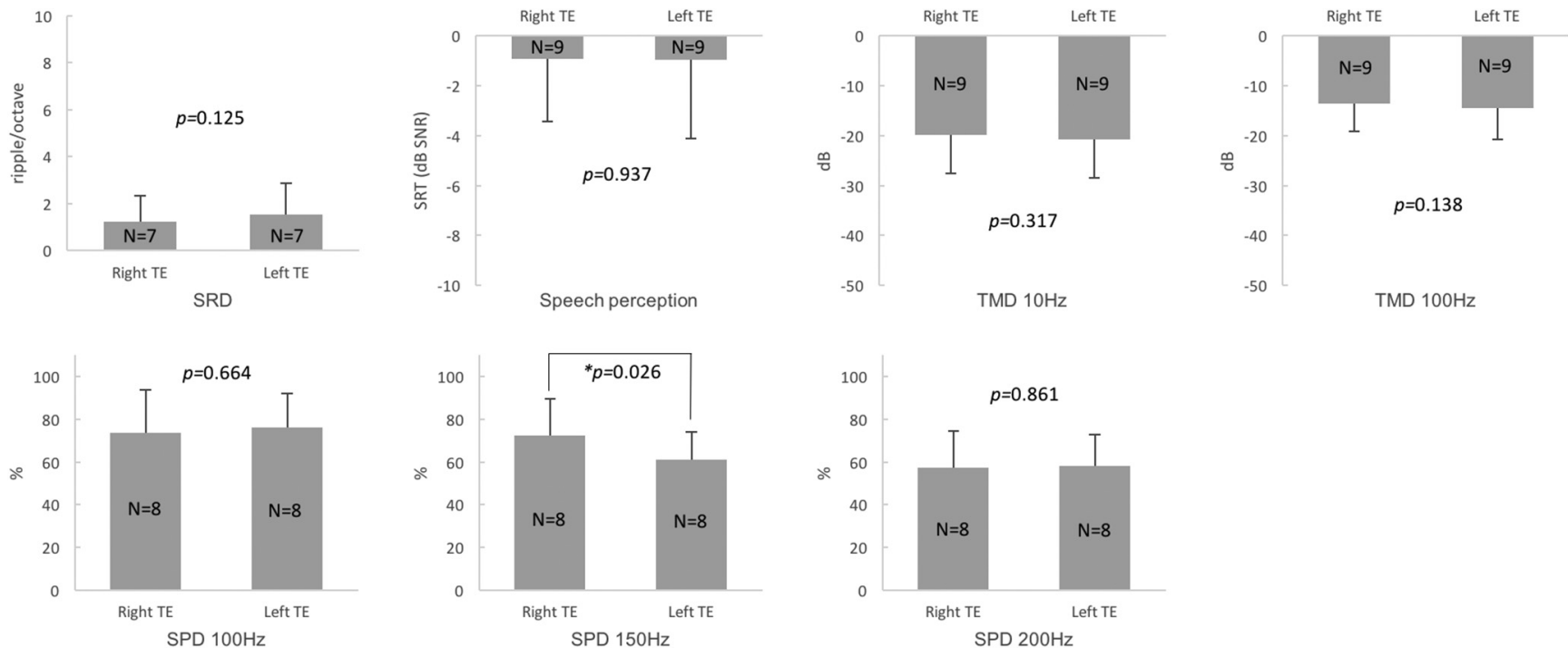

Figure 4. Comparisons of four different psychoacoustic test results between the right and left TEs of bilateral tinnitus subjects with HL and symmetric hearing thresholds. There were no significant differences in the SRD thresholds, SRTs in noise, TMD thresholds, or SPD scores (100 and $200 \mathrm{~Hz}$ ). Only the SPD scores for $150 \mathrm{~Hz}$ showed a significant difference between the right and left TEs.

Table 5. Multiple comparisons among the right and left TEs for Group 3 and control ears for Group 4 with Bonferroni's correction ( ${ }^{*} p<0.017$ )

\begin{tabular}{|c|c|c|c|c|c|c|c|c|c|}
\hline & Bil RTEs $(n=9)$ & Bil LTEs $(n=9)$ & & Bil RTEs $(n=9)$ & Control $(n=15)$ & \multirow[b]{2}{*}{$p$ value } & \multirow{2}{*}{$\frac{\text { Bil LTEs }(n=9)}{\operatorname{Mean}(S D)}$} & \multirow{2}{*}{$\frac{\text { Control }(n=15)}{\text { Mean (SD) }}$} & \multirow[b]{2}{*}{$p$ value } \\
\hline & Mean (SD) & Mean (SD) & $p$ value & Mean (SD) & Mean (SD) & & & & \\
\hline SRD & $1.24(1.08)$ & $1.52(1.36)$ & 0.125 & $1.24(1.08)$ & $3.23(1.85)$ & 0.017 & $1.52(1.36)$ & $3.23(1.85)$ & 0.042 \\
\hline SRT & $-0.91(2.52)$ & $-0.95(3.18)$ & 0.937 & $-0.91(2.52)$ & $-5.15(1.68)$ & $0.000^{*}$ & $-0.95(3.18)$ & $-5.15(1.68)$ & $0.004^{*}$ \\
\hline TMD $10 \mathrm{~Hz}$ & $-19.81(7.80)$ & $-20.82(7.62)$ & 0.317 & $-19.81(7.80)$ & $-23.57(2.26)$ & 0.166 & $-20.82(7.62)$ & $-23.57(2.26)$ & 0.724 \\
\hline TMD $100 \mathrm{~Hz}$ & $-13.51(5.61)$ & $-14.56(6.25)$ & 0.138 & $-13.51(5.61)$ & $-16.47(6.38)$ & 0.166 & $-14.56(6.25)$ & $-16.47(6.38)$ & 0.321 \\
\hline SPD $100 \mathrm{~Hz}$ & $73.75(20.13)$ & 75.94 (16.09) & 0.664 & $73.75(20.13)$ & $91.35(9.82)$ & 0.058 & 75.94 (16.09) & $91.35(9.82)$ & 0.029 \\
\hline SPD $150 \mathrm{~Hz}$ & 72.19 (17.39) & $60.94(13.16)$ & 0.026 & 72.19 (17.39) & 85.58 (12.84) & 0.057 & 60.94 (13.16) & 85.58 (12.84) & $0.008^{*}$ \\
\hline SPD $200 \mathrm{~Hz}$ & 57.19 (17.29) & 58.13 (14.68) & 0.861 & 57.19 (17.29) & 77.50 (11.41) & $0.004^{*}$ & $58.13(14.68)$ & 77.50 (11.41) & $0.003^{*}$ \\
\hline
\end{tabular}

Bil RTEs, Right TEs of bilateral tinnitus group; Bil LTEs, left TEs of bilateral tinnitus group.

*Multiple independent $t$ tests or the Mann-Whitney tests with the Bonferroni's correction, $\alpha=0.05 / 3=0.017$.

noise (poorer speech perception, independent $t$ test, $p=0.004$ ) and lower SPD scores for $150 \mathrm{~Hz}$ (Mann-Whitney test, $p=$ 0.008 ) and for $200 \mathrm{~Hz}$ (independent $t$ test, $p=0.003$ ) were also shown for the left TEs compared with the control ears (Table 5).

\section{Multiple comparisons among the TEs of Groups 1-3}

The multiple comparisons with the Bonferroni correction revealed that the TEs of subjects with normal hearing showed significantly higher SRD thresholds (i.e., better spectral resolution) than the TEs of unilateral tinnitus subjects with HL (independent $t$ test, $p=0.007$ ) or the right and left TEs of bilateral tinnitus subjects with HL (independent $t$ test, $p<0.001$ for both right and left; Fig. 5, Table 6). Lower TMD thresholds for $100 \mathrm{~Hz}$ (i.e., better temporal resolution) were shown for the TEs of subjects with normal hearing than the right TEs of bilateral tinnitus sub- jects with HL (Mann-Whitney test, $p=0.004$ ). Better SPD performance for $150 \mathrm{~Hz}$ was shown for the TEs of subjects with normal hearing than the left TEs of bilateral tinnitus subjects with HL (Mann-Whitney test, $p=0.005$; Fig. 5, Table 6). Overall, these results indicate that the TEs of subjects with normal hearing showed better performance than the TEs of subjects with HL.

\section{Multiple linear regression analyses}

To understand what other factors could potentially affect psychoacoustic performance, multiple linear regression analyses were performed for SRD thresholds, TMD thresholds, SPD scores, and SRTs of the TEs of unilateral tinnitus subjects using various factors including subjects' age, PTA of involved side, tinnitus pitch, symptom duration, tinnitus handicap inventory score, visual analog scale for tinnitus loudness, tinnitus aware- 

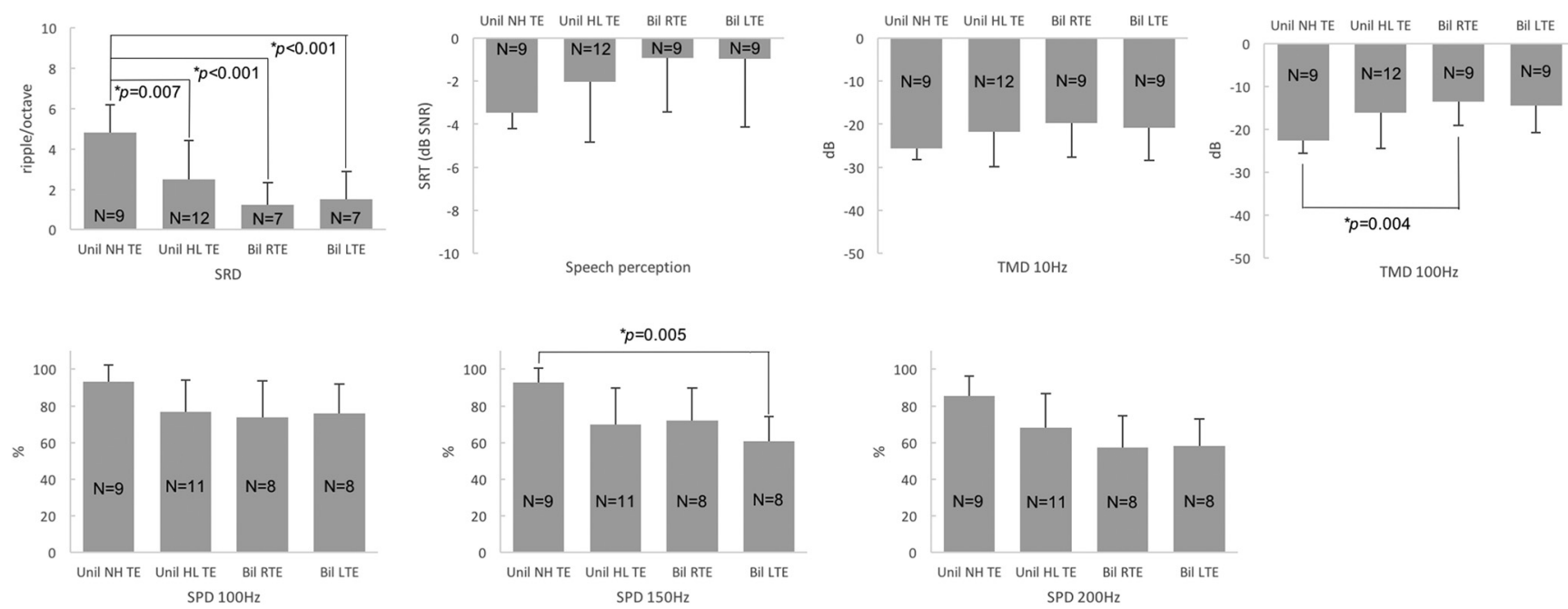

Figure 5. Multiple comparisons among the tinnitus ears of unilateral tinnitus subjects with normal hearing (Unil NH TEs), the tinnitus ears of unilateral tinnitus subjects with HL (Unil HL TEs), and the right and left tinnitus ears of bilateral tinnitus subjects with HL (Bil RTEs and Bil LTEs, respectively). Higher SRD thresholds were shown for Unil NH TEs than Unil HL TEs or Bil RTEs or Bil LTEs. Lower TMD thresholds for $100 \mathrm{~Hz}$ were shown for Unil NH TEs than Bil RTES, and higher SPD scores for $150 \mathrm{~Hz}$ were shown for Unil NH TEs than Bil LTEs.

Table 6. Multiple-comparisons $p$ values among TEs for Groups 1 and 2 and the right and left TEs for Group 3 with Bonferroni's correction $\left({ }^{*} p<0.008\right)$

\begin{tabular}{lllllll}
\hline & Unil NH TEs vs Unil HL TEs & Unil NH TEs vs Bil RTEs & Unil NH TEs vs Bil LTEs & Unil HL TEs vs Bil RTEs & Unil HL TEs vs Bil LTEs & Bil RTEs vs Bil LTEs \\
\hline SRD & $0.007^{*}$ & $0.000^{*}$ & $0.000^{*}$ & 0.140 & 0.262 & 0.125 \\
SRT & 0.107 & 0.016 & 0.046 & 0.357 & 0.420 & 0.937 \\
TMD 10 Hz & 0.315 & 0.024 & 0.049 & 0.404 & 0.385 & 0.317 \\
TMD 100 Hz & 0.026 & $0.004^{*}$ & 0.008 & 0.385 & 0.507 & 0.138 \\
SPD 100 Hz & 0.021 & 0.064 & 0.030 & 0.727 & 0.912 & 0.664 \\
SPD 150 Hz & 0.027 & 0.023 & $0.005^{*}$ & 0.805 & 0.490 & 0.026 \\
SPD 200 Hz & 0.043 & 0.012 & 0.009 & 0.207 & 0.221 & 0.861 \\
\hline
\end{tabular}

Unil NH TEs, TEs of unilateral tinnitus group with normal hearing (Group 1); Uni HL TEs, TEs of unilateral tinnitus group with hearing loss (Group 2); Bil RTEs, right TEs of bilateral tinnitus group with hearing loss (Group 3); Bil LTEs, left TEs of bilateral tinnitus group with hearing loss (Group 3).

*Multiple independent $t$ tests or the Mann-Whitney tests with the Bonferroni's correction, $\alpha=0.05 / 6=0.008$.

ness score, and Beck depression inventory score. These analyses showed that these factors did not affect performance for the four different psychoacoustic tests. Interestingly, subject age was found to be a significant factor determining SPD scores $(p=$ 0.021; Table 7).

\section{Correlation analyses}

Figure 6 shows that SRD thresholds significantly correlated with SRTs in noise for the 35 TEs of Groups 1, 2, and 3 ( $r=-0.514$, $p=0.002$ ). For the 36 NTEs of Groups 1,2 , and 4 , SRD thresholds also significantly correlated with SRTs in noise $(r=-0.380, p=$ 0.022). As shown in Figure 7, TMD thresholds for both 10 and $100 \mathrm{~Hz}$ significantly correlated with SRTs in noise for the 39 TEs of the Groups 1, 2, and 3 ( $r=0.600, p<0.001$ for $10 \mathrm{~Hz} ; r=$ $0.574, p<0.001$ for $100 \mathrm{~Hz}$ ). For the 36 NTEs of Groups 1, 2, and 4 , nonsignificant correlations were found between TMD thresholds and SRTs in noise $(r=0.574, p=0.199$ for $10 \mathrm{~Hz} ; r=0.230$ $p=0.176$ for $100 \mathrm{~Hz}$ ).

\section{Discussion}

The results of the current study demonstrate that effects of tinnitus on the auditory spectral and temporal resolution and speech perception in noise were nearly consistent in unilateral tinnitus subjects with normal hearing threshold (Group 1), unilateral tinnitus subjects with HL (Group 2), and bilateral tinnitus subjects with HL (Group 3). Poorer speech perception was shown for the TEs than for the NTEs in subjects with symmetric hearing regardless of whether they had normal hearing. However, we could not find any evidence showing poorer spectral resolution or temporal resolution in the TEs than in the NTEs. The auditory spectral and temporal resolution may be attributed to the status of OHCs. Initial cochlear damage starts from the OHCs and disturbance of the active movement of the OHCs makes the basilar membrane response more linear and broadly tuned (Glasberg and Moore, 1986; Oxenham and Bacon, 2003). The reduced compression and the broadening of the auditory filters negatively affect both frequency selectivity and temporal resolution (Glasberg and Moore, 1986; Moore and Glasberg, 1988; Moore and Oxenham, 1998; Oxenham and Bacon, 2003). Using monkeys given ototoxic drugs, Smith et al. (1987) showed that, at frequencies corresponding to the region of complete $\mathrm{OHC}$ loss, there was a selective attenuation of tip of the psychophysical tuning curve. Although there may be multiple components that could potentially affect spectral and temporal processing in the human auditory system, we speculate that no inferiority of spectral/temporal resolution in the TEs compared with the NTEs implies that there may be no more OHC damage in the tinnitus side. Especially in the unilateral tinnitus subjects with normal hearing, including extended high frequencies (Group 1), we predict that the conditions of cochlear hair cells are likely to be intact and similar on both sides.

We hypothesized that minimal peripheral damage that does not affect hearing detection thresholds could worsen spectral resolution and/or temporal resolution of hearing and this damage could be a cause of unilateral tinnitus in subjects with symmetric 
Table 7. Multiple linear regression analyses of various factors and SRD thresholds, temporal modulation detection thresholds, SPD scores, and speech recognition thresholds in the TEs of unilateral tinnitus subjects

\begin{tabular}{|c|c|c|c|c|}
\hline Psychoacoustic tests & Factors & Standardized $\beta$ Coefficient & $r^{2}$ & $p$ value \\
\hline \multirow[t]{8}{*}{ Spectral-ripple thresholds } & Age & -0.163 & \multirow[t]{8}{*}{0.698} & 0.709 \\
\hline & PTA & -0.967 & & 0.055 \\
\hline & Pitch & 0.086 & & 0.706 \\
\hline & Duration & 0.110 & & 0.602 \\
\hline & THI & -0.447 & & 0.136 \\
\hline & VAS & 0.532 & & 0.145 \\
\hline & TAS & 0.104 & & 0.633 \\
\hline & BDI & 0.076 & & 0.730 \\
\hline \multirow[t]{8}{*}{ TMD thresholds } & Age & 0.524 & \multirow[t]{8}{*}{0.803} & 0.159 \\
\hline & PTA & -0.043 & & 0.907 \\
\hline & Pitch & 0.200 & & 0.290 \\
\hline & Duration & -0.201 & & 0.251 \\
\hline & $\mathrm{THI}$ & 0.461 & & 0.066 \\
\hline & VAS & 0.257 & & 0.366 \\
\hline & TAS & -0.156 & & 0.383 \\
\hline & BDI & -0.264 & & 0.160 \\
\hline \multirow[t]{8}{*}{ SPD scores } & Age & -0.941 & \multirow[t]{8}{*}{0.807} & $0.021^{*}$ \\
\hline & PTA & -0.022 & & 0.951 \\
\hline & Pitch & -0.082 & & 0.652 \\
\hline & Duration & 0.344 & & 0.063 \\
\hline & THI & -0.367 & & 0.127 \\
\hline & VAS & 0.145 & & 0.600 \\
\hline & TAS & 0.217 & & 0.232 \\
\hline & BDI & 0.141 & & 0.429 \\
\hline \multirow[t]{8}{*}{ SRTS } & Age & -0.301 & \multirow[t]{8}{*}{0.649} & 0.524 \\
\hline & PTA & 0.912 & & 0.086 \\
\hline & Pitch & -0.106 & & 0.664 \\
\hline & Duration & -0.321 & & 0.175 \\
\hline & THI & 0.131 & & 0.667 \\
\hline & VAS & 0.242 & & 0.518 \\
\hline & TAS & -0.293 & & 0.229 \\
\hline & BDI & -0.146 & & 0.540 \\
\hline
\end{tabular}

Mean SPD and TMD thresholds averaged across multiple frequencies were used for this analysis.

THI, Tinnitus handicap inventory; VAS, visual analogue scale of the loudness; TAS, tinnitus awareness score; BDI, Beck depression inventory.

${ }^{*} p<0.05$.

hearing thresholds. However, the results from the current study do not support this hypothesis. Moreover, when we take into consideration of the finding that the bilateral tinnitus subjects showed similar SRTs in noise between the right and left TEs, the poorer speech perception for the TEs compared with the NTEs of unilateral tinnitus subjects may be related to tinnitus effects. In general, spectral and temporal envelope cues have a large influence on speech perception (Baer and Moore, 1993; Henry et al., 2005), consistent with the results of correlation data in the present study. However, poorer speech perception in noise was shown in the TEs than in the NTEs even though neither spectral resolution nor temporal resolution differed between the TEs and NTEs. To reconcile these two findings, we speculate that tinnitus may affect central auditory system as "a central masker" to interrupt speech perception rather than the peripheral auditory system and that tinnitus might have not hindered spectral/temporal process in our subjects.

Conversely, the decoupling of the SRT results from the spectral/temporal resolution data could imply that the occurrence of tinnitus does not depend upon the degree of damage to the $\mathrm{OHCs}$, but rather upon different plastic changes in the central auditory system after the same degree of cochlear damage. In other words, the plastic changes in central auditory system induced by deafferentation may vary despite the same amount of end organ damage and tinnitus may develop in selective cases. Numerous unknown factors can increase the synchrony of single neuron activities, unmask dormant synapses, create new connections between neurons, or increase the spontaneous activity in central auditory system due to the lack of auditory input (Bartels et al., 2007; Roberts et al., 2010; Noreña and Farley, 2013).

We further investigated the difference in tinnitus effects among each group. Better spectral resolution found in the TEs in the unilateral tinnitus group with normal hearing (Group 1) than the TEs in other tinnitus groups with HL (Group 2 and 3) may be attributed by younger ages and better hearing acuities of Group 1 . The better performance observed in TMD and SPD in the TEs in the unilateral tinnitus subjects with normal hearing (Group 1) than in the TEs of bilateral tinnitus subjects with HL (Group 3) might be caused by the same reasons described above rather than the unilaterality of tinnitus. As for the SRT in noise, the TEs in Group 1 showed much lower thresholds (i.e., better speech perception) than the right or left TEs in Group 3 (independent $t$ test, $p=0.0159$ and 0.0455, respectively; Fig. 6); however, it did not reached significance after Bonferroni correction at the $\alpha$ level of 0.008 (i.e., $0.05 / 6=0.008$ ). We could not find any different performance between the unilateral tinnitus subjects with $\mathrm{HL}$ (Group 2) and the bilateral tinnitus subjects with HL (Group 3).

In a study that compared the results of the hearing-in-noise test between young tinnitus subjects with normal hearing $\leq 8$ $\mathrm{kHz}$ and normal hearing age-matched controls, the SRTs were significantly higher in the tinnitus group under all test conditions (Ryu et al., 2012). These results agree well with our results. However, the test setting of the Ryu et al. (2012) study differed from our study. First, we compared the TEs and NTEs in unilateral tinnitus subjects with symmetric hearing thresholds because we expected that significant individual variability would be shown for speech perception in noise. Indeed, other studies also emphasized within-subject design in the clinical trial for tinnitus because tinnitus is likely to have different subgroups and affects people differently (Tyler et al., 2007). Second, when the tinnitus subjects showed a pure-tone threshold of $<20 \mathrm{~dB}<8 \mathrm{kHz}$, we excluded those showing different bilateral hearing thresholds at extended high frequencies $>8 \mathrm{kHz}$. Sanches et al. (2010) studied the auditory temporal resolution of normal hearing subjects with tinnitus using the gap-in-noise test and found poorer temporal resolution in the tinnitus group, which is in contrast to the results of the present study. This discrepancy could be attributed to the enrollment of subjects with hearing impairment at extended high frequencies or a difference in the test modality for temporal resolution. The use of intensity cues in the gap-in-noise test is contentious. Indeed, an increased intensity discrimination threshold was found in tinnitus subjects with normal audiograms compared with the audiometrically matched control group (Epp et al., 2012). A recent study using psychoacoustic measurements showed better frequency selectivity and compression in tinnitus subjects than in subjects without tinnitus with similar average HL (Tan et al., 2013). From these results, the investigators suggested that the presence of tinnitus may not be associated with $\mathrm{OHC}$ damage, but rather with inner hair cell dysfunction, and that the consequent reduced auditory innervation may trigger tinnitus. In our study using a different psychoacoustic measure for spectral resolution, SRD, the frequency selectivity of the TEs was the same as that of the NTEs in the same group of subjects.

There is an important issue about the definition of symmetric hearing thresholds in this study because we considered that there are nearly same statuses of bilateral auditory systems when both ears show symmetric hearing thresholds. In the literature (Zakis 

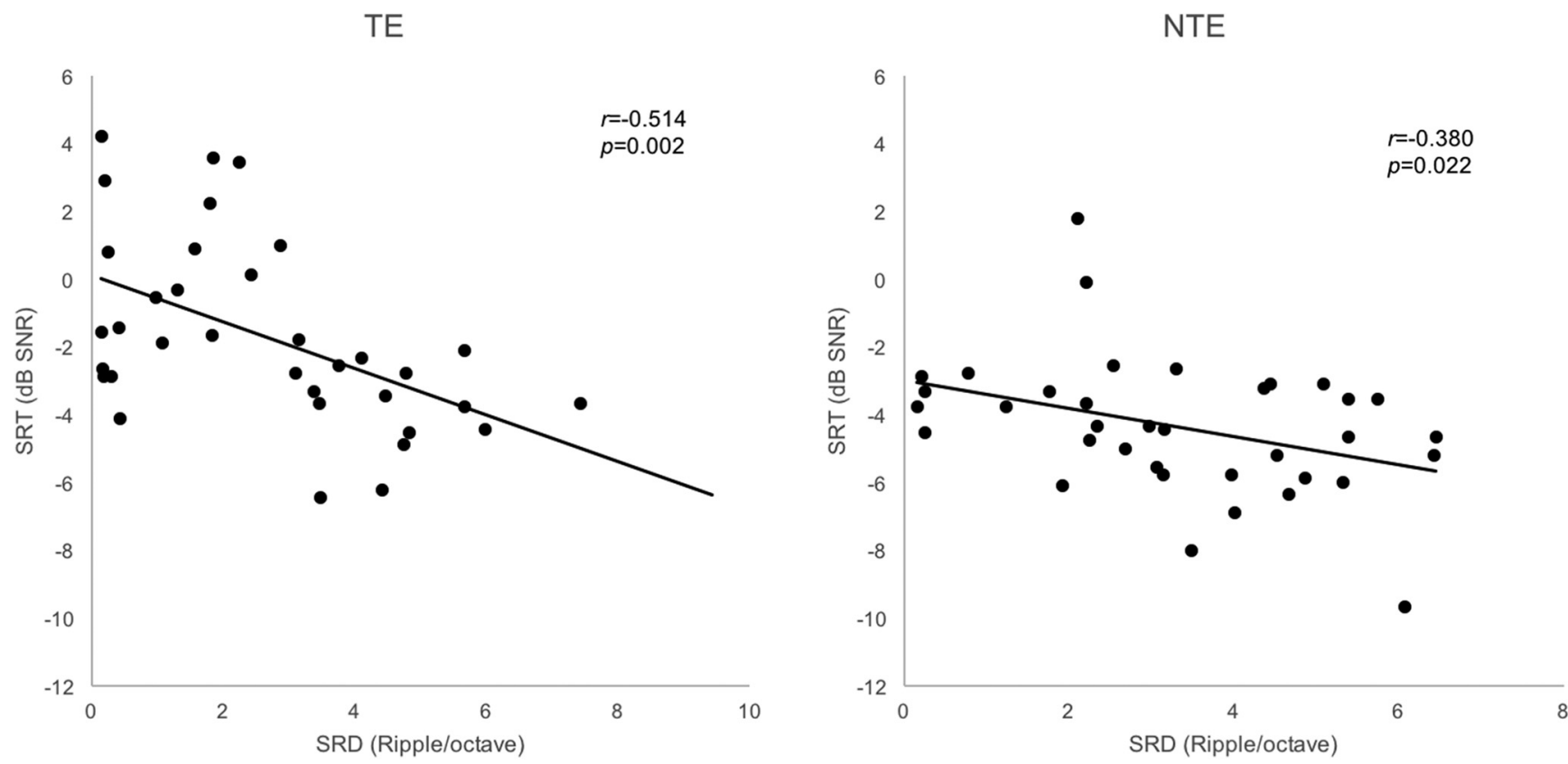

Figure 6. SRD thresholds correlated with SRTs in noise for the 35 TEs of Groups 1, 2, and 3. For the 36 NTEs of Groups 1, 2, and 4, the SRD thresholds also correlated with SRTs in noise.

TE

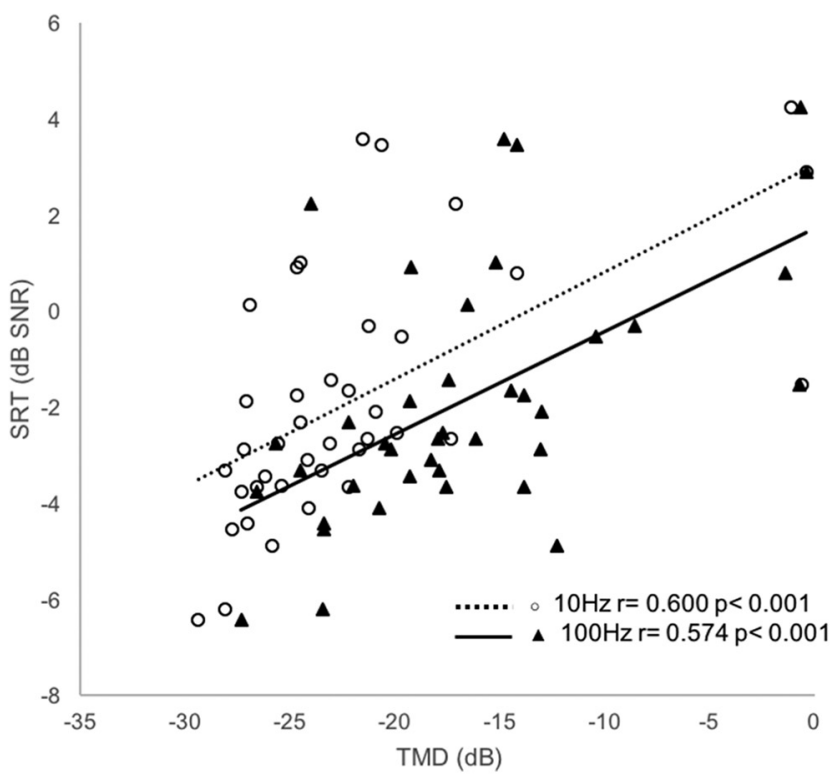

NTE

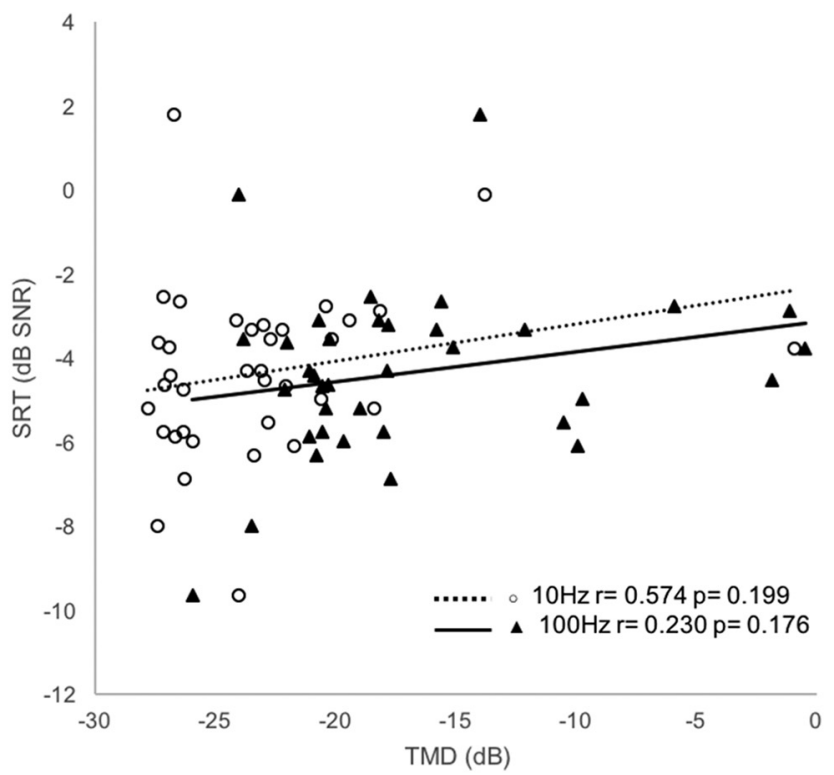

Figure 7. Both TMD thresholds ( 10 and $100 \mathrm{~Hz}$ ) correlated with SRTs in noise for the 39 TEs of the Groups 1, 2, and 3 . For the 36 NTEs of Groups 1, 2, and 4, nonsignificant correlations were found between TMD thresholds and SRTs in noise.

et al., 2009; Ching et al., 2013; Akeroyd et al., 2014; Van Esch et al., 2015), $10 \mathrm{~dB}$ (or even $20 \mathrm{~dB}$ ) criteria for defining symmetrical hearing has been often used because pure-tone thresholds are usually repeatable within a range of $\pm 5 \mathrm{~dB}$. However, we applied more strict criteria for symmetric hearing thresholds (see Materials and Methods).

The limitation of the present study was that subjects who had relatively low hearing thresholds and a relatively low handicap (tinnitus handicap inventory scores of $46.6 \pm 27.8$ ) were enrolled. Because unilateral tinnitus subjects with higher ipsilateral hearing thresholds are more common in clinical practice, it is difficult to conclude that our results represent the whole mechanism of tinnitus after cochlear damage. Nonetheless, enrolling unilateral tinnitus subjects with symmetric hearing thresholds may be the best way to exclude the effects of elevated hearing thresholds on psychoacoustic performance and to avoid individual variations. There might be an argument to classify the subgroups in this study because subjective loudness or annoyance also may affect the psychoacoustic performance. For example, Tyler et al. (2008) suggested that subgroups should be classified with tinnitus loudness, pitch variance, emotional status, sleep disturbance, and the influence of noise to adopt specific clinical trial of tinnitus treatment. 
The major findings from the current study are twofold. First, tinnitus can constrain patients' speech perception ability in noise regardless of their hearing sensitivity despite the fact that tinnitus had no influence upon spectral and temporal resolution of hearing. This finding suggests that tinnitus may affect central auditory system as a central masker when patients are engaged to listen to speech in the presence of background noise. Second, the plastic changes in the central auditory system induced by deafferentation rather than end-organ damage itself might be critical for the occurrence of tinnitus.

\section{References}

Akeroyd MA, Guy FH, Harrison DL, Suller SL (2014) A factor analysis of the SSQ (Speech, Spatial, and Qualities of Hearing Scale). Int J Audiol 53: 101-114. CrossRef Medline

Ami M, Abdullah A, Awang MA, Liyab B, Saim L (2008) Relation of distortion product otoacoustic emission with tinnitus. Laryngoscope 118: 712-717. CrossRef Medline

Baer T, Moore BC (1993) Effects of spectral smearing on the intelligibility of sentences in noise. J Acoust Soc Am 94:1229-1241. CrossRef

Bartels H, Staal MJ, Albers FW (2007) Tinnitus and neural plasticity of the brain. Otol Neurotol 28:178-184. CrossRef Medline

Ching TY, Johnson EE, Hou S, Dillon H, Zhang V, Burns L, van Buynder P, Wong A, Flynn C (2013) A comparison of NAL and DSL prescriptive methods for paediatric hearing-aid fitting: Predicted speech intelligibility and loudness. Int J Audiol 52:S29-S38. CrossRef Medline

Dooling RJ, Leek MR, Gleich O, Dent ML (2002) Auditory temporal resolution in birds: discrimination of harmonic complexes. J Acoust Soc Am 112:748-759. CrossRef Medline

Drennan WR, Longnion JK, Ruffin C, Rubinstein JT (2008) Discrimination of Schroeder-phase harmonic complexes by normal-hearing and cochlear-implant listeners. J Assoc Res Otolaryngol 9:138-149. CrossRef Medline

Epp B, Hots J, Verhey JL, Schaette R (2012) Increased intensity discrimination thresholds in tinnitus subjects with a normal audiogram. J Acoust Soc Am 132:EL196-201. Medline

Fabijańska A, Smurzyński J, Hatzopoulos S, Kochanek K, Bartnik G, RajKoziak D, Mazzoli M, Skarżyński PH, Jędrzejczak WW, Szkiełkowska A, Skarżyński H (2012) The relationship between distortion product otoacoustic emissions and extended high-frequency audiometry in tinnitus patients. Part 1: Normally hearing patients with unilateral tinnitus. Med Sci Monit 18:CR765-CR770. Medline

Glasberg BR, Moore BC (1986) Auditory filter shapes in subjects with unilateral and bilateral cochlear impairments. J Acoust Soc Am 79:10201033. CrossRef Medline

Gouveris H, Maurer J, Mann W (2005) DPOAEgrams in patients with acute tonal tinnitus. Otolaryngol Head Neck Surg 132:550-553. CrossRef Medline

Henry BA, Turner CW, Behrens A (2005) Spectral peak resolution and speech recognition in quiet: normal hearing, hearing impaired, and cochlear implant listeners. J Acoust Soc Am 118:1111-1121. CrossRef Medline

Job A, Raynal M, Kossowski M (2007) Susceptibility to tinnitus revealed at 2 $\mathrm{kHz}$ range by bilateral lower DPOAEs in normal hearing subjects with noise exposure. Audiol Neurootol 12:137-144. CrossRef Medline

Lauer AM, Molis M, Leek MR (2009) Discrimination of time-reversed harmonic complexes by normal-hearing and hearing-impaired listeners. J Assoc Res Otolaryngol 10:609-619. CrossRef Medline

Léger AC, Moore BC, Lorenzi C (2012) Abnormal speech processing in frequency regions where absolute thresholds are normal for listeners with high-frequency hearing loss. Hear Res 294:95-103. CrossRef Medline

Léger AC, Ives DT, Lorenzi C (2014) Abnormal separation of competing speech signals in frequency region where absolute thresholds are normal for listeners with high-frequency hearing loss. Hear Res 316:102-109. CrossRef Medline

Levitt H (1971) Transformed up-down methods in psychoacoustics. J Acoust Soc Am 49:467-477. CrossRef Medline

Moore BC, Glasberg BR (1988) Gap detection with sinusoids and noise in normal, impaired, and electrically stimulated ears. J Acoust Soc Am 83: 1093-1101. CrossRef Medline

Moore BC, Oxenham AJ (1998) Psychoacoustic consequences of compression in the peripheral auditory system. Psychol Rev 105:108-124. CrossRef Medline

Noreña AJ, Farley BJ (2013) Tinnitus-related neural activity: theories of generation, propagation, and centralization. Hear Res 295:161-171. CrossRef Medline

Onishi ET, Fukuda Y, Suzuki FA (2004) Distortion product otoacoustic emissions in tinnitus patients. Int Tinnitus J 10:13-16. Medline

Oxenham AJ, Bacon SP (2003) Cochlear compression: perceptual measures and implications for normal and impaired hearing. Ear Hear 24:352-366. Medline

Pan T, Tyler RS, Ji H, Coelho C, Gehringer AK, Gogel SA (2009) The relationship between tinnitus pitch and the audiogram. Int J Audiol 48: 277-294. CrossRef Medline

Preece JP, Tyler RS, Noble W (2003) The management of tinnitus. Geriatrics and Aging 6:22-28,

Roberts LE, Eggermont JJ, Caspary DM, Shore SE, Melcher JR, Kaltenbach JA (2010) Ringing ears: the neuroscience of tinnitus. J Neurosci 30:1497214979. CrossRef Medline

Ryu IS, Ahn JH, Lim HW, Joo KY, Chung JW (2012) Evaluation of masking effects on speech perception in patients with unilateral chronic tinnitus using the hearing in noise test. Otol Neurotol 33:1472-1476. CrossRef Medline

Sanches SG, Sanchez TG, Carvallo RM (2010) Influence of cochlear function on auditory temporal resolution in tinnitus patients. Audiol Neurootol 15:273-281. CrossRef Medline

Schaette R, McAlpine D (2011) Tinnitus with a normal audiogram: Physiological evidence for hidden hearing loss and computational model J Neurosci 31:13452-13457. CrossRef

Shim HJ, Kim SK, Park CH, Lee sH, Yoon SW, Ki AR, Chung DH, Yeo SG (2009) Hearing abilities at ultra-high frequency in patients with tinnitus. Clin Exp Otorhinolaryngol 2:169-174. CrossRef Medline

Shiomi Y, Tsuji J, Naito Y, Fujiki N, Yamamoto N (1997) Characteristics of DPOAE audiogram in tinnitus patients. Hear Res 108:83-88. CrossRef Medline

Smith DW, Moody DB, Stebbins WC, Norat MA (1987) Effects of outer hair cell loss on the frequency selectivity of the patas monkey auditory system. Hear Res 29:125-138. CrossRef Medline

Tan CM, Lecluyse W, McFerran D, Meddis R (2013) Tinnitus and Patterns of Hearing Loss. J Assoc Res Otolaryngol 14:275-282. CrossRef Medline

Tyler RS, Oleson J, Noble W, Coelho C, Ji H (2007) Clinical trials for tinnitus: Study populations, designs, measurement variables, and data analysis. Prog Brain Res 166:499-509. CrossRef Medline

Tyler R, Coelho C, Tao P, Ji H, Noble W, Gehringer A, Gogel S (2008) Identifying tinnitus subgroups with cluster analysis. Am J Audiol 17:S176-S184

Tyler RS, Pienkowski M, Roncancio ER, Jun HJ, Brozoski T, Dauman N, Coelho CB, Andersson G, Keiner AJ, Cacace AT, Martin N, Moore BC (2014) A Review of hyperacusis and future directions: Part I. Definitions and manifestations. Am J Audiol 23:402-419. CrossRef Medline

Van Esch TV, Lutman ME, Vormann M, Lyzenga J, Hällgren M, Larsby B, Athalye SP, Houtgast T, Kollmeier B, Dreschler WA (2015) Relations between psychophysical measures of spatial hearing and self-reported spatial-hearing abilities. Int J Audiol 54:182-189. CrossRef Medline

Weisz N, Hartmann T, Dohrmann K, Schlee W, Norena AJ (2006) Highfrequency tinnitus without hearing loss does not mean absence of deafferentation. Hear Res 222:108-114.

Won JH, Drennan WR, Rubinstein JT (2007) Spectral-ripple resolution correlates with speech perception in noise in cochlear implant users. J Assoc Res Otolaryngol 8:384-392. CrossRef Medline

Won JH, Drennan WR, Nie K, Jameyson EM, Rubinstein JT (2011) Acoustic temporal modulation detection and speech perception in cochlear implant listeners. J Acoust Soc Am 130:376-388. CrossRef Medline

Zakis JA, Hau J, Blamey PJ (2009) Environmental noise reduction configuration: Effects on preferences, satisfaction, and speech understanding. Int J Audiol 48:853-867. CrossRef Medline 